\title{
NUMERICAL SIMULATION OF INDUSTRIAL DUST DISTRIBUTION IN THE TERRITORY OF ZESTAFONI, GEORGIA
}

\author{
NATIA G. GIGAURI ${ }^{1}$, LEILA V. GVERDTSITELI ${ }^{1}$, \\ ALEKSANDRE A. SURMAVA ${ }^{2,3} \&$ LIANA N. INTSKIRVELI ${ }^{3}$ \\ ${ }^{1}$ Georgian Technical University, Tbilisi, Georgia \\ ${ }^{2}$ M. Nodia Institute of Geophysics, I. Javakhishvili Tbilisi State University, Georgia \\ ${ }^{3}$ Institute of Hydrometeorology, Georgian Technical University, Tbilisi, Georgia
}

\begin{abstract}
Dust distribution of the industrial town of Zestafoni located in the complex territory of Georgia in case of basic meteorological situations and stationary pollution sources is studied with the use of regional model of atmospheric process development in the Caucasus and non-stationary threedimensional equation of transfer-diffusion of passive admixtures. Distribution patterns of dust dissipated in the atmosphere are obtained at different levels from the surface. It is shown that dust dissipated from cities in the atmosphere is basically concentrated in the boundary layer. Maximum values of dust concentration are obtained in the lower $100 \mathrm{~m}$ of surface air layer. Spatial dust distribution region increases and concentration decreases along with height increase. An influence of local orography on the pollution cloud is investigated. During a background western light air Likhi and Racha ridges impede dust transfer to the east and cause dust cloud deformation. Dust spreads along the valleys of Kvirila and Chkherimela rivers located between the ridges. In the case of gentle and fresh breezes the impact of local orography on the dust dispersion process is insignificant. Dust is basically transferred in the direction of background flows. The zone of influence of industrial town dust on the environmental pollution is determined. A width of this area varies from 5 to $20 \mathrm{~km}$ in dependence of the background wind velocity. Kinematics of dust propagation is studied. It is determined that in 2-100 $\mathrm{m}$ layer of atmosphere the process of turbulent diffusion takes precedence in the process of dust spreading. From $100 \mathrm{~m}$ to $1 \mathrm{~km}$ the processes of diffusive and advective transfers are identical, while above $1 \mathrm{~km}$ the preference is given to advective transfer.
\end{abstract}

Keywords: atmospheric air pollution, Zestafoni dust distribution, numerical simulation.

\section{INTRODUCTION}

Reduction of atmospheric dust pollution in big cities and industrial centres is a global problem of human health and environment protection [1]. Lots of practical measures and scientific researches need to be conducted for accomplishment of this goal [2]-[4]. Numerical 3D models are elaborated, which are widely used for the modeling of regional, mesoscale local dust transfer-diffusion and study of dust pollution problems of separate industrial centers [5]-[19].

The problem of atmospheric air pollution is vital for industrial areas of Georgia. Zestafoni city draws attention in this context, where the object of ferrous metallurgy Georgian Manganese LLC and other smaller enterprises of this profile are situated. Thousands of big and small vehicles move back and forth everyday on Transcaucasus highway, which is component part of the Silk Road. As a result, large quantities of dust, manganese and other solid and gaseous aerosols are emitted in the atmosphere. Therefore, as the observations show, dust concentration in the air of stationary observation points located in relatively clean dwelling zones of the city is equal or exceeds the value of oneoff maximum allowable concentration ( $\mathrm{MAC}=0.5 \mathrm{mg} / \mathrm{m}^{3}$ ) (Fig. 1) [20]. High dust content in city atmosphere may have negative impact on general ecological state of the adjacent 


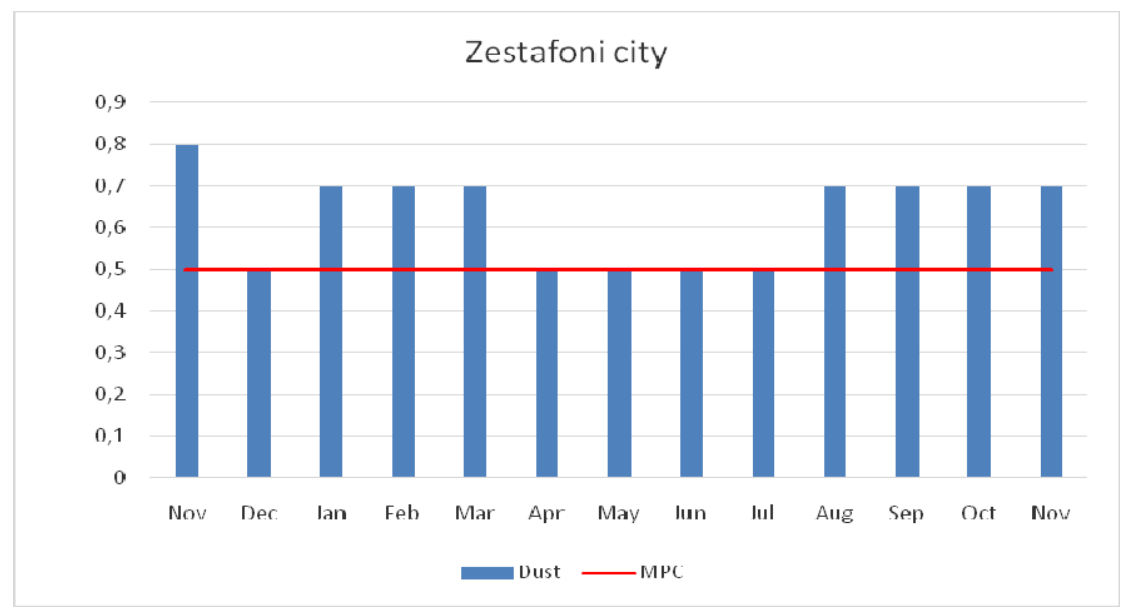

Figure 1: Monthly average dust concentrations $\left(\mathrm{mg} / \mathrm{m}^{3}\right)$ from November 2016 to December 2017.

territory. The adjacent territory of Zestafoni is of great cultural-recreational and touristic importance. Zestafoni is known for high-quality grapes for production of champagne and dry wines.

There are located Tskhaltubo and Sairme - resorts of international importance, as well as tourist attractions - Borjomi-Kharagauli and Ajameti national parks, Sataplia and Prometheus cave within a distance of $50 \mathrm{~km}$ from the city. That is why the knowledge of dispersion and spatial distribution of polluting agents is of great practical importance in order to carry out environmental protection measures. Respectively, application of numerical modeling methods for dispersion of polluting agents in the atmosphere is very effective for solution of the mentioned problem.

\section{GOAL SETTING}

Zestafoni region is distinguished with complex terrain. Lowland territory, mesoscale ridge oriented along the meridians and parallels and valleys located between ridges alter each other there. Terrain height within $50 \mathrm{~km}$ radius varies from $50 \mathrm{~m}$ to $2.5 \mathrm{~km}$.

Terrain-tracing coordinate system [21] and the following equation system are used in order to take into account the impact of complex terrain:

(a) for the troposphere

$$
\begin{gathered}
\frac{\mathrm{du}}{\mathrm{dt}}=-\frac{\overline{\mathrm{P}}}{\rho} \frac{\partial \varphi}{\partial \mathrm{x}}+\operatorname{lv}+\mathrm{g}(1+0.61 \mathrm{q}) \vartheta \frac{\partial \mathrm{z}}{\partial \mathrm{x}}+\mu \Delta \mathrm{u}+\frac{1}{\rho \mathrm{h}^{2}} \frac{\partial}{\partial \zeta} \rho v \frac{\partial \mathrm{u}}{\partial \zeta}, \\
\frac{d v}{d t}=-\frac{\bar{P}}{\rho} \frac{\partial \varphi}{\partial \mathrm{y}}-l u+g(1+0.61 q) \vartheta \frac{\partial \mathrm{z}}{\partial y}+\mu \Delta v+\frac{1}{\rho h^{2}} \frac{\partial}{\partial \zeta} \rho v \frac{\partial v}{\partial \zeta}, \\
\frac{\partial \varphi}{\partial \zeta}=\frac{\mathrm{g}}{\mathrm{RT}}(1+0.61 \mathrm{q}) \vartheta \mathrm{h}, \\
\frac{\partial \mathrm{h}}{\partial \mathrm{t}}+\frac{\partial \mathrm{uh}}{\partial \mathrm{x}}+\frac{\partial \mathrm{vh}}{\partial \mathrm{y}}+\frac{\partial \widetilde{\mathrm{w}}}{\partial \zeta}+\frac{1}{\rho} \frac{\mathrm{d} \rho}{\mathrm{dz}} \mathrm{wh}=0,
\end{gathered}
$$




$$
\begin{gathered}
\frac{\partial \vartheta}{\partial \mathrm{t}}+\mathrm{u} \frac{\partial \vartheta}{\partial \mathrm{x}}+\mathrm{v} \frac{\partial \vartheta}{\partial \mathrm{y}}+\widetilde{\mathrm{w}} \frac{\partial \vartheta}{\partial \zeta}+\mathrm{Sw}=\mu \Delta \vartheta+\frac{1}{\rho \mathrm{h}^{2}} \frac{\partial}{\partial \zeta} \rho v \frac{\partial \vartheta}{\partial \zeta}+\frac{\mathrm{L}}{\rho \mathrm{C}_{\mathrm{p}}} \phi_{\mathrm{con}}, \\
\frac{\partial \mathrm{q}}{\partial \mathrm{t}}+\mathrm{u} \frac{\partial \mathrm{q}}{\partial \mathrm{x}}+\mathrm{v} \frac{\partial \mathrm{q}}{\partial \mathrm{y}}+\widetilde{\mathrm{w}} \frac{\partial \mathrm{q}}{\partial \zeta}=\mu \Delta \mathrm{q}+\frac{1}{\mathrm{~h}^{2}} \frac{\partial}{\partial \zeta} v \frac{\partial \mathrm{q}}{\partial \zeta}-\varphi_{\mathrm{con}}, \\
\frac{\partial m}{\partial \mathrm{t}}+u \frac{\partial m}{\partial \mathrm{x}}+v \frac{\partial m}{\partial y}+\widetilde{w} \frac{\partial m}{\partial \zeta}+=\mu \Delta m+\frac{\partial}{\mathrm{h}^{2} \partial \zeta} v \frac{\partial m}{\partial \zeta}+\varphi_{c o n}, \\
\frac{\mathrm{d}}{\mathrm{dt}}=\frac{\partial}{\partial \mathrm{t}}+\mathrm{u} \frac{\partial}{\partial \mathrm{x}}+\mathrm{v} \frac{\partial}{\partial \mathrm{y}}+\widetilde{\mathrm{w}} \frac{\partial}{\partial \zeta}, \\
\Delta=\frac{\partial}{\partial \mathrm{x}^{2}}+\frac{\partial}{\partial \mathrm{y}^{2}}, \quad \mathrm{w}=\frac{\partial \mathrm{z}}{\partial \mathrm{t}}+\mathrm{u} \frac{\partial \mathrm{z}}{\partial \mathrm{x}}+\mathrm{v} \frac{\partial \mathrm{z}}{\partial \mathrm{y}}+\widetilde{\mathrm{w} h} \mathrm{C}
\end{gathered}
$$

(b) for active soil layer

$$
\frac{\partial \mathrm{C}}{\partial \mathrm{t}}=\frac{\partial}{\partial \mathrm{z}} \mathrm{D}(\mathrm{C}) \frac{\partial \mathrm{C}}{\partial \mathrm{z}}-\frac{\partial \mathrm{E}(\mathrm{C})}{\partial \mathrm{z}}, \frac{\partial \mathrm{T}_{\text {soil }}}{\partial \mathrm{t}}=\mathrm{K}_{\text {soil }} \frac{\partial^{2} \mathrm{~T}_{\text {soil }}}{\partial \mathrm{z}^{2}} \text {, at } \delta_{0}>\mathrm{z}>\mathrm{Z}_{\text {soil }}
$$

where: $\mathrm{t}$ is time; $\mathrm{x}, \mathrm{y}$ and $\mathrm{z}$ are the axes of the Cartesian coordinate directed to the east, north and vertically upwards, respectively; $\zeta=(\mathrm{z}-\delta) / \mathrm{h}$ is the dimensionless vertical coordinate; $\delta(\mathrm{x}, \mathrm{y})$ is the height of the relief; $\mathrm{H}(\mathrm{t}, \mathrm{x}, \mathrm{y})$ is the height of the tropopause; $\mathrm{h}=\mathrm{H}-\delta ; \mathrm{u}, \mathrm{v}, \mathrm{w}$ and $\widetilde{\mathrm{w}}$ are the wind velocity components along the axes $\mathrm{x}, \mathrm{y}, \mathrm{z}$ and $\zeta$, respectively; $\vartheta=\left(\mathrm{T}^{\prime}+\overline{\overline{\mathrm{T}}}\right) / \overline{\mathrm{T}}$, and $\varphi=\left(\mathrm{P}^{\prime}+\overline{\overline{\mathrm{P}}}\right) / \overline{\mathrm{P}}$ are the analogues of temperature and pressure, respectively; $\bar{T}=300 \mathrm{~K} ; \mathrm{T}^{\prime}$ and $\mathrm{P}^{\prime}$ are the deviations of temperature and pressure from the standard vertical distributions $\mathrm{P}^{\prime}(\mathrm{t}, \mathrm{x}, \mathrm{y}, \mathrm{z})_{2} \mathrm{P}(\mathrm{t}, \mathrm{x}, \mathrm{y}, \mathrm{z})_{-} \overline{\mathrm{P}}(\mathrm{z})-\overline{\overline{\mathrm{P}}}(\mathrm{t}, \mathrm{x}, \mathrm{y}, \mathrm{z})$; $\mathrm{T}^{\prime}=\mathrm{T}(\mathrm{t}, \mathrm{x}, \mathrm{y}, \mathrm{z})-\overline{\mathrm{T}}+\gamma \mathrm{z}-\overline{\overline{\mathrm{T}}}(\mathrm{t}, \mathrm{x}, \mathrm{y}, \mathrm{z}) ; \mathrm{T}$ and $\mathrm{P}$ are the temperature and pressure of the atmosphere, respectively: $\overline{\mathrm{T}}-\gamma \mathrm{z}$ and $\overline{\mathrm{P}}(\mathrm{z})$ are the standard vertical distributions of the temperature and pressure, respectively; $\gamma_{\text {is }}$ the standard vertical temperature gradient; $\overline{\bar{T}}$ and $\overline{\overline{\mathrm{P}}}$ are the background deviations of the temperature and pressure from standard vertical distributions; $\mathrm{T}_{\text {soil }}$ is the soil temperature; $\mathrm{C}$ is the volume content of soil water; $\rho(z)$ is the standard vertical distributions of the densities of dry air; $g$ is the gravitational acceleration; $\mathrm{R}$ is the universal gas constant for dry air; ${ }^{C_{p}}$ is the specific heat capacity of dry air at constant pressure; $S$ is the thermal stability parameter; $L$ is the latent heat of condensation; $\phi_{\text {con }}$ is the condensation rate; D is the diffusion coefficient of water in soil; $E$ is the filtration coefficient of water in a soil; $I_{\text {sea }}$ is the total solar radiation flux in sea water; $\mathrm{K}_{\text {soil }}$ is the thermal diffusivity coefficients of soil; $\mu$ and $v$ are the horizontal and vertical turbulent diffusion coefficients. 
For the meteorological fields in the surface layer of atmosphere with thickness of $100 \mathrm{~m}$ there is used a parameterization method [22]:

$$
\begin{gathered}
\frac{\partial|\overrightarrow{\mathrm{u}}|}{\partial \mathrm{z}}=\frac{\mathrm{u}_{*}}{\chi \mathrm{z}} \varphi_{\mathrm{u}}(\varsigma), \frac{\partial \mathrm{p}}{\partial \mathrm{z}}=\frac{\mathrm{p}_{*}}{\mathrm{z}} \varphi_{\vartheta}(\varsigma),\left(\mathrm{p}_{*}=\vartheta, q\right), \quad \varsigma=\frac{\mathrm{z}}{\mathrm{L}}, \mathrm{L}=\frac{\mathrm{u}_{*}^{2}}{\lambda \chi^{2} \vartheta_{*}^{2}} \\
|\overrightarrow{\mathrm{u}}|=\frac{\mathrm{u}_{*}}{\chi} \mathrm{f}_{\mathrm{u}}\left(\varsigma, \varsigma_{\mathrm{u}}\right), \mathrm{p}-\mathrm{p}_{0}=\mathrm{p}_{*} \mathrm{f}_{\vartheta}\left(\varsigma, \varsigma_{0}\right), \quad \varsigma_{\mathrm{u}}=\frac{\mathrm{z}_{\mathrm{u}}}{\mathrm{L}}, \varsigma_{0}=\frac{z_{0}}{\mathrm{~L}}, \quad \text { if } \quad \mathrm{z} \leq \mathrm{z}_{\text {sur }},
\end{gathered}
$$

where $\mathrm{Z}_{\mathrm{u}}$ - is the roughness; ${ }^{\mathrm{Z}_{\vartheta}}$-parameter, which depends on properties of underlying surface and is a known function; $\mathrm{z}_{\text {sur }}$ and $\mathrm{z}_{0}$ - known constants; $\mathrm{u}_{*}$-dynamic velocity; $\lambda$ and $\chi_{-}$buoyancy parameter and Karman constant; $\varphi_{u}(\varsigma), \varphi_{\vartheta}(\varsigma), f_{u}\left(\varsigma, \varsigma_{u}\right)$ and $f_{\vartheta}\left(\varsigma, \varsigma_{0}\right)$ are the universal functions of similarity theory.

In the free atmosphere and surface layer of atmosphere for diffusion of contaminant the following equation is used:

$$
\frac{\partial \operatorname{Con}}{\partial t}+u \frac{\partial \operatorname{Con}}{\partial x}+v \frac{\partial \operatorname{Con}}{\partial y}+\left(\widetilde{w}-\frac{W_{\text {sed }}}{h}\right) \frac{\partial \text { Con }}{\partial \zeta}=\mu \Delta \operatorname{Con}+\frac{\partial}{\partial \zeta} v \frac{\partial \operatorname{Con}}{\partial \varsigma},
$$

where $C$ is the dust concentration; $\mathrm{W}_{\text {sed }}$ is an aerosol deposition velocity.

Eqns (1)-(4) systems are solved by numerical way using initial and boundary conditions. Conditions are selected according to the specific task.

Numerical integration of eqn (1) is made using scheme [23], eqn (2) - with the use of Crank-Nicolson scheme, eqn (3) is solved according to method given in [19], eqn (4) - with the use of Crank-Nicolson scheme and splitting method. Rectangular finite difference grid $118 \times 90 \times 31$, with $0.8 \mathrm{~km}$ horizontal step and $1 / 31$ vertical step is used. The surface layer height is $100 \mathrm{~m}$ from soil level. Number of vertical levels in the surface layer is equal to 17 , and vertical grid step varies in interval $2-15 \mathrm{~m}$. The time step is $5 \mathrm{sec}$.

\section{RESULTS OF MODELING}

The distributions of the anthropogenic dust emitted in the atmosphere from Zestafoni city in cases of background western light air, gentle and fresh breezes are numerically modeled. The data of National Environment Agency [20] Con $=0.8 \mathrm{mg} / \mathrm{m}^{3}$ are taken as the initial and boundary values at the $2 \mathrm{~m}$ height in atmosphere at the territory of Zestafoni. The initial concentration of dust at the points of the network that do not belong to cities is considered equal to zero. The diameter of dust particle is assumed to be equal to $10 \mu \mathrm{m}$.

Spatial distribution of dust concentrations in June during background western light air ( $\mathrm{u}_{\text {backg }} \approx 1 \mathrm{~m} / \mathrm{s}$ on $\mathrm{z}=10 \mathrm{~m}$ and growths to $\mathrm{u}_{\text {backg }} \approx 20 \mathrm{~m} / \mathrm{s}$ on $\mathrm{z}=9 \mathrm{~km}$ ), when $\mathrm{t}=24$ hours and $\mathrm{z}=2,100,600$ and $1000 \mathrm{~m}$ height from earth surface obtained by calculations, is shown on Fig. 2. Concentration values are calculated in units of maximum allowable concentration (MAC $=0.5 \mathrm{mg} / \mathrm{m}^{3}$ ) of dust.

As is seen from the Fig. 2, dust concentrations at 2 and $100 \mathrm{~m}$ height are maximal at the territory of city and in their direct vicinity (Fig. 2(a) and (b)). In surface layer of the atmosphere dust cloud has the form of vertical cylinder deformed in northern and southern directions. Maximum concentration is obtained directly in vicinity of city at $2 \mathrm{~m}$ height, approximately in $12 \mathrm{~km}^{2}$ area. This zone is gradually decreases with height increase and at 


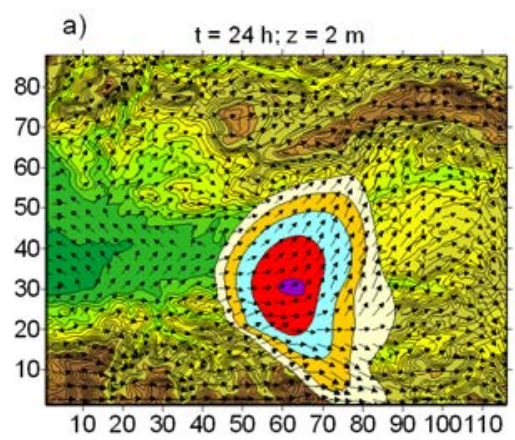

b)

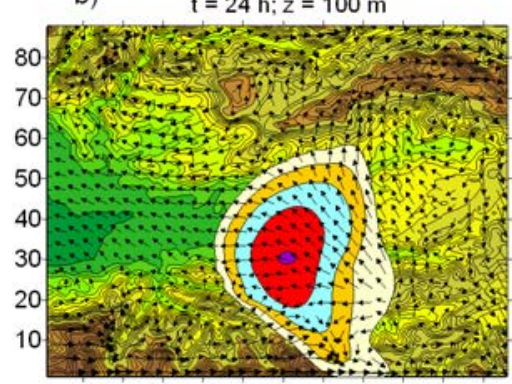

102030405060708090100110 c)

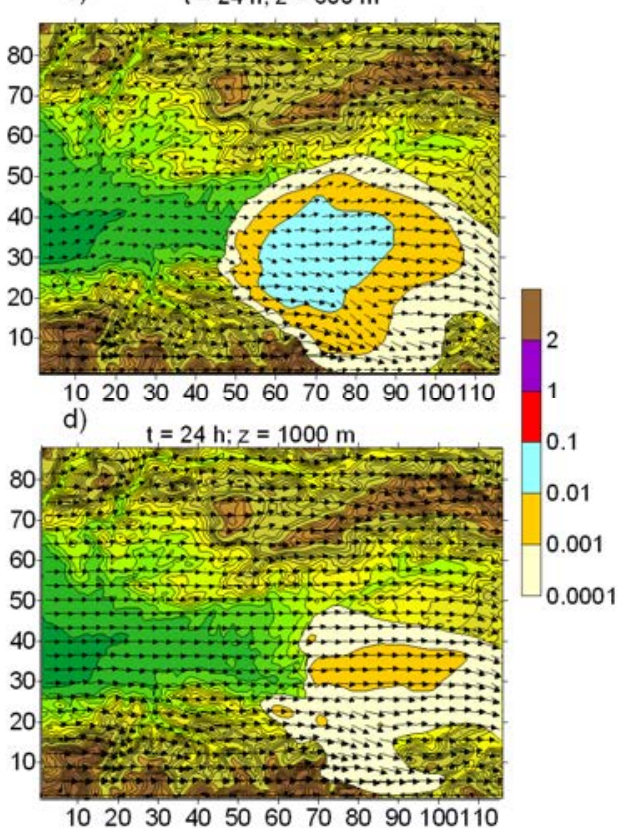

Figure 2: Distribution of wind velocity and dust concentration $\mathrm{C}$ at $\mathrm{z}=2,100,600$ and $1000 \mathrm{~m}$ height from earth surface in case of background western light air, when $\mathrm{t}=24 \mathrm{~h}$. (Numbers on the axes are the steps.)

$100 \mathrm{~m}$ height maximum concentration is obtained approximately in $3 \mathrm{~km}^{2}$ area. Dust is distributed both in windward direction and in the direction opposite to wind. Dust dispersal area in opposite direction is negligibly small that is caused by reciprocal action of horizontal turbulent and advective dispersion. To the contrary, in windward direction processes of advective and turbulent transfer have one and the same direction. The shape of dust cloud obtained by calculations shows that in the process of dust dispersal in surface layer of the atmosphere the share of turbulent diffusion and horizontal advection is roughly the same according to its value. As a result dust cloud becomes significantly deformed and takes oblong form, especially in the zones of local wind velocity increase - along the valleys of Kvirila and Chkherimela rivers (Fig. 2(a) and (b)).

In the boundary atmospheric layer (when $\mathrm{z}>100 \mathrm{~m}$ ) the area of dust distribution enlarges. Dust advection exceeds turbulent diffusion (Fig. 2(c) and (d)).

Mentioned effects are obviously seen in the Fig. 3, where the distribution of zonal component of wind velocity and concentration of dust are shown in XOZ plane in atmosphere boundary layer. It is seen from Fig. 3 that dust is dispersed in 2-2.5 km surface layer of the atmosphere. $0.1-1$ MAC concentration values are obtained in approximately 12 $\mathrm{km}$ long and $0.8 \mathrm{~km}$ thick layers of atmospheric air, 0.01-0.1 MAC values in $21 \mathrm{~km}$ long and $1.5 \mathrm{~km}$ thick layer and 0.01-0.001 MAC - in $35 \mathrm{~km}$ long and $2 \mathrm{~km}$ thick layer. In the windward side the dust is dispersed approximately at $8 \mathrm{~km}$ distance, while in the leeward side - at $27 \mathrm{~km}$ distance. Dust concentration distribution in the cloud is not uniform. Concentration is maximum in the central part of cloud and gradually decreases towards the periphery. 


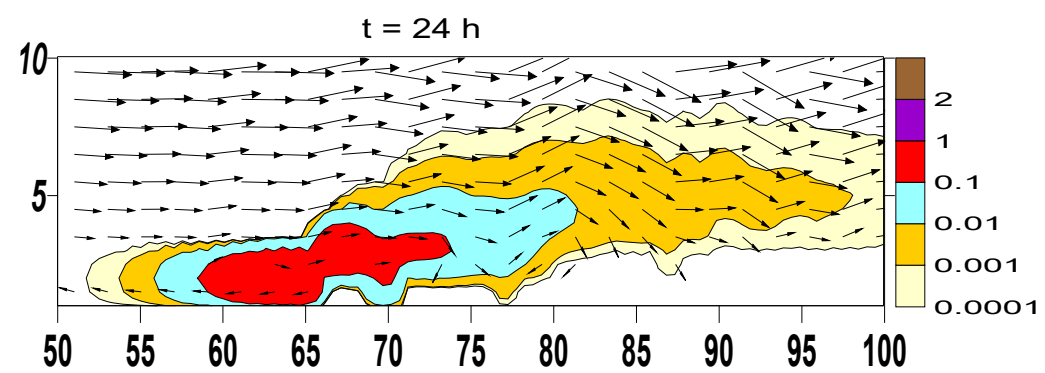

Figure 3: Distribution of wind velocity and dust concentration $\mathrm{C}$ in $3 \mathrm{~km}$ layer of atmosphere in XOZ plane passing accros Zestafoni city in case of background western light air. (Numbers on the axes are the steps.)

In case of the background gentle breeze during 24 hours the dust disperses at significantly large territories than in case of background light air (Fig. 4). The dust is transferred both in background wind direction and transversely to it. Dynamical action of the Likhi Ridge is the reason of such expansion of pollution. A part of the dust stream under action of Likhi Ridge changes direction of movement and distributed along the Kvirila and Chkherimela rivers gorges.

Turbulent transfer of the dust in atmospheric boundary layer is relatively weak compared with advective transfer, and as a result in the vicinity of Zestafoni dust virtually is not propagated at windward side of the city.

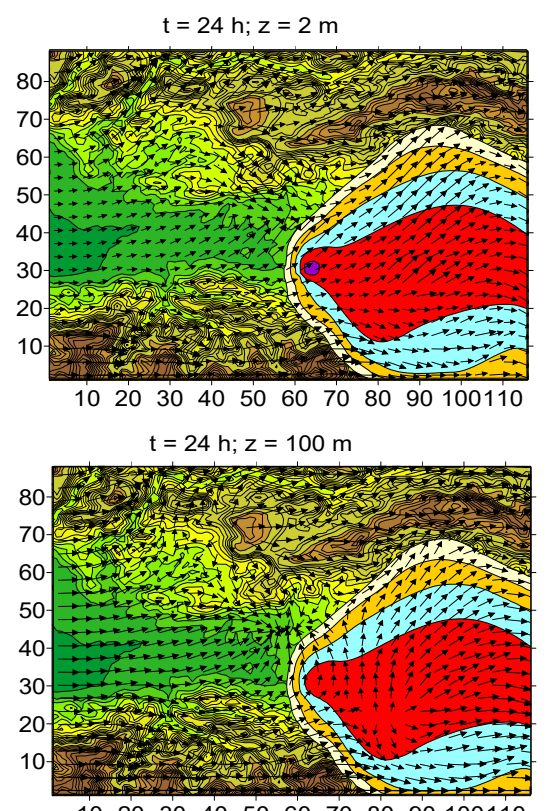

102030405060708090100110

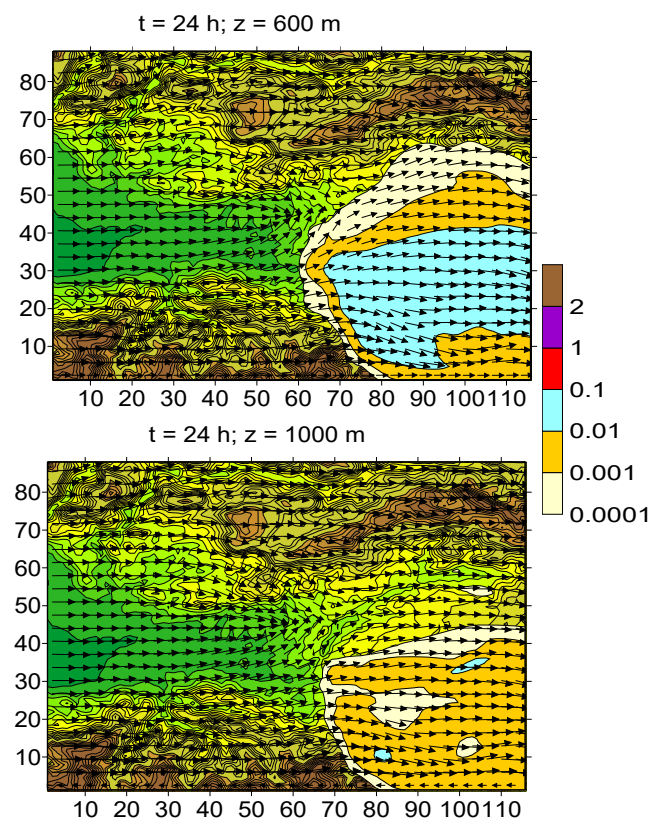

102030405060708090100110

Figure 4: Distribution of wind velocity and dust concentration $\mathrm{C}$ at $\mathrm{z}=2,100,600$ and $1000 \mathrm{~m}$ height from earth surface in case of background western gentle breeze, when $t=24 h$. (Numbers on the axes are the steps.) 
In the Fig. 5 distribution of wind velocity and dust concentration $\mathrm{C}$ in atmospheric boundary layer ( $\mathrm{Z} \leq 3 \mathrm{~km}$ ) in XOZ plane in case of background western gentle breeze are shown. Dust concentration is maximum in the central part of dust cloud and is getting smaller towards its upper and lower boundaries. Vertical movements originated by the terrain cause dust cloud deformation and division of maximum concentration zones into separate parts.

Qualitatively similar dust distribution is obtained in case of background western fresh breeze ( $u_{\text {backg }} \approx 10 \mathrm{~m} / \mathrm{s}$ ). The difference is only of quantitative nature - during fresh breeze dust is propagated at larger area and its displacement occurs faster. It is determined according to calculations that dust transfer velocity in case of light air and fresh breeze equals to approximately 0.6 and 0.8 parts of background velocity.

In the Fig. 6 graphics of concentration $\mathrm{C}(\mathrm{x})$ in XOZ plane when $\mathrm{z}=2,100$ and $600 \mathrm{~m}$ lines 1,2 and 3, respectively; $\mathrm{j}=31$ and $\mathrm{t}=24 \mathrm{~h}$ in case of background western gentle breeze are shown. From this figure we can see that at $5 \mathrm{~km}$ distance from pollution source vertical change of dust concentration takes place in $600 \mathrm{~m}$ atmospheric layer above ground. At greater distances the concentration at these levels is one and the same and gradually reduces with distance from the point of pollution.

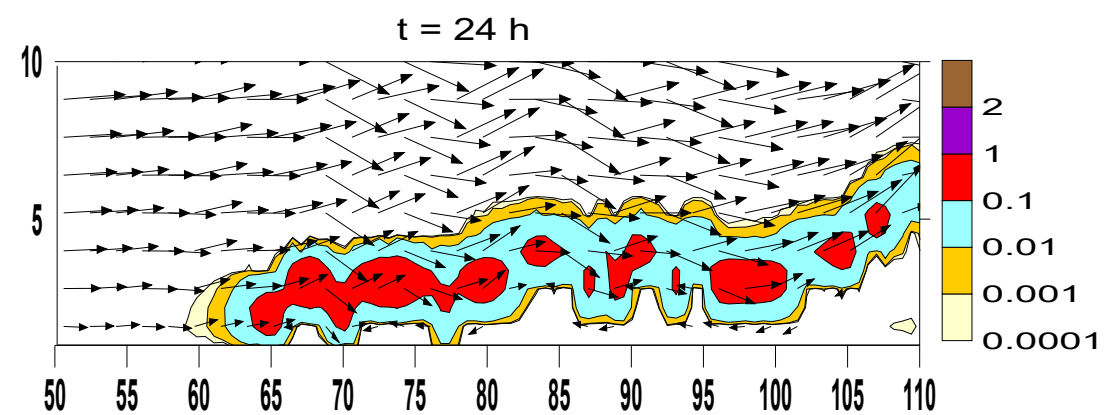

Figure 5: Distribution of wind velocity and dust concentration $\mathrm{C}$ in $3 \mathrm{~km}$ layer of atmosphere in XOZ plane passing accros Zestafoni city in case of background western gentle breeze. (Numbers on the axes are the steps.)

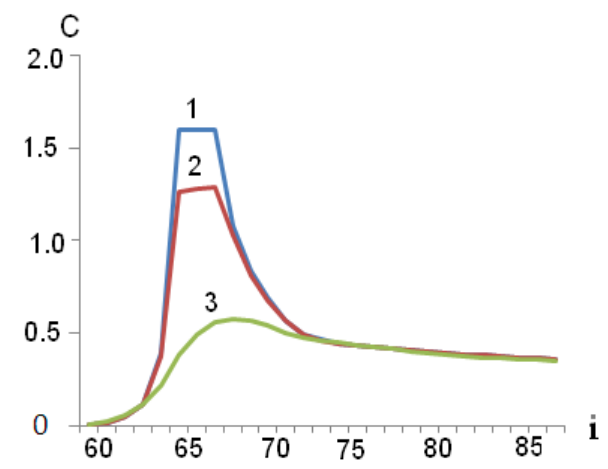

Figure 6: Graphics of concentration $\mathrm{C}(\mathrm{x})$ in $\mathrm{XOZ}$ plane. (Numbers on the horizontal axis is the steps.) 


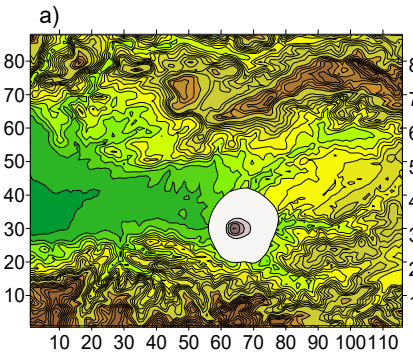

$10203040506070 \quad 8090100110$ b)

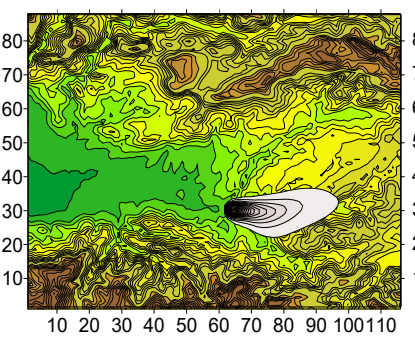

c)

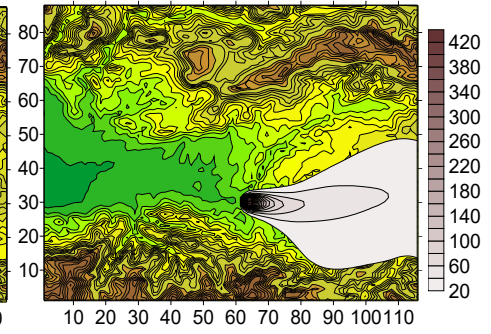

Figure 7: Surface density of the dust deposited on the soil $\left(\mathrm{mg} / \mathrm{m}^{2}\right)$. (Numbers on the axes are the steps.)

In the Fig. 7 the surface density of the dust deposited on the ground during 24 hours in cases of background western light air (a); gentle breeze (b); and fresh breeze (c) is shown. It is seen that in cases of background light air and gentle breeze the dust is deposited both on the circle and ellipse-like territory with the approximately $200 \mathrm{~km}^{2}$ area. In case of background fresh breeze wind the area of dust deposition is significantly bigger. It looks like a strip directed from the west to the east, length of which exceeds $50 \mathrm{~km}$, while the width is approximately $28 \mathrm{~km}$. In all considered cases the quantity of dust deposited in Zestafoni on $1 \mathrm{~m}^{2}$ during 24 hours is almost the same and equals to $400 \mathrm{mg}$.

\section{CONCLUSION}

Thus, the carried out numerical modeling has manifested some meteorological peculiarities, which are characteristic for dust dispersal process under urban conditions in Zestafoni region. In case of western light air dust concentration in $100 \mathrm{~m}$ surface layer of the atmosphere above Zestafoni is roughly the same. Above the surface atmospheric layer this concentration rapidly decreases and at $3 \mathrm{~km}$ height becomes equal to zero. In vertical profile dust concentration is bigger in the centre of cloud and is getting smaller towards the periphery.

Orography causes deformation of pollution cloud. On the windward side of Likhi ridge, due to orography influence dust dispersal eastward is inhibited and starts to shift predominantly in north-east and south-east directions along the valleys of Kvirila and Chkherimela rivers. At that, on the windward side of the ridge upward movement caused by orography decreases dust sedimentation process. As a result the density of deposited dust at large distances from dust pollution sources is negligible.

As a result of the resistant action of mountain ridgeoriented in meridian direction, the velocity of advective diffusion of the urban dust is less than the velocity of the background wind and varies in interval of 0.6-0.8 parts of the background wind velocity for the light air and fresh breeze, respectively.

Comparison of results obtained by calculations with actual results is very important. Natural observations at the territory adjacent to Zestafoni are scheduled for this end.

\section{ACKNOWLEDGEMENT}

This work was supported by Shota Rustaveli National Science Foundation (SRNSF) (PhDF-17-192, Numerical modeling of the manganese pollution of the environmental objects in the Zestafoni industrial region). 


\section{REFERENCES}

[1] World Health Organization, Global Health Risk: Mortality and Burden of Diseases Attributable to Selected Major Risks, pp. 23-53, 2009.

[2] Novak, L., Bizjan, B., Pražnikar, J., Horvat, B., Orbanić, A.A. \& Širok, B., Numerical modeling of dust lifting from a complex-geometry industrial stockpile. Journal of Mechanical Engineering, 611, pp. 621-631, 2015. DOI: 10.5545/sv-jme. 2015.2824.

[3] Fedotov, V., Gorbacheva, A., Dorodnikova, A. \& Yerokhina, M., Cleaning of atmospheric air in a city street and road network as an environmental safety technology for road transport. Transportation Research Procedia, 20, pp. 200-204, 2017.

[4] Zhonglin, Xu., Fundamentals of Air Cleaning Technology and its Application in Clean Rooms. Springer Science \& Business Media: Berlin, 2013.

[5] Ginoux, P. et al., Sources and distributions of dust aerosols simulated with the GOCART model. Journal of the Geophysical Research, 106, pp. 255-273, 2001.

[6] Shlichkov, V.A., Malbakhov, V.M. \& Leghenin, A.A., Numerical modeling of atmospheric circulation and transfer of contaminating impurities in Norilsk Valley. Atmospheric and Oceanic Optics, 18, pp. 490-496, 2013 (in Russian).

[7] Surmava, A.A., Mishveladze, B.A. \& Davitashvili, T., Numerical modeling of the pollution transfer in the Caucasus atmosphere from hypothetical source in case of the background western wind. Journal of the Georgian Geophysical Society, 13B, pp. 15-21, 2009.

[8] Surmava, A.A., Numerical investigation of the modeling of transportation and deposition of the radioactive pollution in the Caucasian region in case of the hypothetical accident on the Armenian nuclear power plant. Journal of the Georgian Geophysical Society, 15B, pp. 32-45, 2012.

[9] Villasenor, R., López-Villegas, M.T., Eidels-Dubovoi, S., Quintanar, A. \& Gallardo, J.C., A mesoscale modeling study of wind-blown dust on the Mexico City basin. Atmospheric Environment, 37, pp. 2451-2462, 2003.

[10] Wang, J. et al., Mesoscale modeling of smoke transport over the southeast Asian maritime continent: Interplay of sea breeze, trade wind, typhoon, and topography. Atmospheric Research, 122, pp. 486-503, 2013.

[11] Penenko, V.V. \& Aloyan, A.E., Models and Methods for Environmental Protection Tasks. Nauka: Novosibirsk, 1985 (in Russian).

[12] Aloyan, A.E., Penenko, V.V. \& Kozoderov, V.V., Mathematical modeling in environmental issues. Modern Problems of Computational Mathematics and Mathematical Modeling, 2, pp. 279-351, 2005 (in Russian).

[13] Aloyan, A.E. \& Arutinian, V.O., Modeling of gaseous admixtures and aerosols evolution in atmosphetic disperse systems. www.sscc.ru/Conf/mmg2008/papers/ aloyan.doc, 2008.

[14] Aloyan, A. E., Modeling of Dynamics and Kinetics of Gaseous Admixtures and Aerosols in the Atmosphere. Nauka: Moscow, 2008 (in Russian).

[15] Long, J. et al., A monitoring and modeling study to investigate regional transport and characteristic of $\mathrm{PM}_{2.5}$ pollution. Aerosol and Air Quality Research, 13, pp. 943-956, 2013.

[16] Ginoux, P. et al., Sources and distributions of dust aerosols simulated with the GOCART model. Journal of the Geophysical Research, 106, pp. 255-273, 2001.

[17] Jose, R.S., Perez, J.L., Morant, J.L. \& Gonzalez, R.M., Simulations of $\mathrm{PM}_{2.5}$ and other pollutants during Winter 2003 in Germany: A model experiment within MM5- 
CMAQ and WRF/CHEM models. Ukrainian Hydrometeorological Journal, 4, pp. 202-2009, 2009.

[18] Perez, C. et al., Atmospheric dust modeling from meso- to global scales with the online NMMB/BSC-dust model - Part 1: Model description, annual simulations and evaluation. Atmospheric Chemistry and Physics, 11, pp. 13001-13027, 2011. doi:10.5194/acp-11-13001-2011.

[19] Perez C. et al., A long Saharan dust event over the Western Mediterranean: Lidar, sun photometer observations, and regional dust modeling. Journal of Geophysical Research, 111, D15214, 2006. doi:10.1029/2005JD006579.

[20] Georgian National Environmental Agency. Short review of Georgia Environment Pollution. www.nea.gov.ge (in Georgian).

[21] Gutman, L.N., Introduction to the Nonlinear Theory of Mesoscale Meteorological Processes. Gidrometeoizdat: Leningrad, 1969 (in Russian).

[22] Kazakov, A.L. \& Lazriev, G.L., On parametrization of atmospheric boundry layer and active soil layer. Izvestia. Atmospheric and Ocean Physics, 15, pp. 257-265, 1978.

[23] Shuman, F.G. \& Hovermale, L.R., An operational six-layer primitive equation model. Journal of Applied Mechanics, 7, pp. 525-547, 1968. 